\title{
Molecular tectonics: on the formation of 1-D silver coordination networks by thiacalixarenes bearing nitrile groups
}

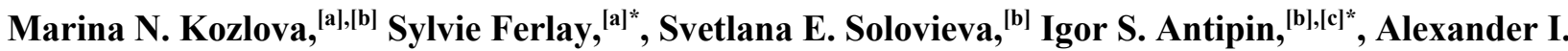 \\ Konovalov, ${ }^{[b]}$ Nathalie Kyritsakas, ${ }^{[a]}$ Mir Wais Hosseini ${ }^{[a]^{*}}$ \\ ${ }_{5}$ Receipt/Acceptance Data [DO NOT ALTER/DELETE THIS TEXT] \\ Publication data [DO NOT ALTER/DELETE THIS TEXT] \\ DOI: 10.1039/b000000x [DO NOT ALTER/DELETE THIS TEXT]
}

Two new p-tertbutylthiacalix[4]arene derivatives $\mathbf{2}$ and $\mathbf{3}$ decorated at the lower rim with four nitrile groups have been prepared and structurally characterised in the crystalline phase. The two 10 ligands, differing by the length of the spacer between the calix moiety and the nitrile group, adopt the 1,3-alternate conformation in the solid state. The ligand $\mathbf{3}$ bearing four $\left(\mathrm{CH}_{2}\right)_{3} \mathrm{CN}$ fragments behaves as a tecton in the presence of silver salts $\left(\mathrm{AgX}, \mathrm{X}=\mathrm{BF}_{4}, \mathrm{PF}_{6}\right.$ or $\left.\mathrm{SbF}_{6}\right)$ and leads to the formation of analogous 1-D linear coordination networks. The tecton $\mathbf{3}$ acts as a bis chelate unit and bridges consecutive silver cations adopting a tetrahedral coordination geometry. Anions and

15 solvent molecules occupy the free space between networks and exhibit no specific interactions with the cationic architecture.

\section{Introduction}

The design, formation and characterisation of coordination networks, infinite periodic architectures formed upon mutual 20 interconnection between organic units and metal centres or metal complexes are areas of current interest. ${ }^{1}$ Molecular tectonics is an efficient and operational approach in this area. $^{2-7}$ It is based on two main principles which are specific coordination events taking place between organic and metallic 25 construction units called tectons ${ }^{6}$ leading to an assembling pattern and the iteration of the process transforming the latter into the nodes of the network. Thus, for coordination networks, the organic tecton must offer coordinating sites (often donor hetero elements) and the metal centre or metal 30 complex must possess free coordination sites. The formation of coordination networks occurs under self-assembly processes (for crystalline materials during the crystallisation event) and one of the driving forces is the establishment of coordination bonds between the donor sites located on the 35 organic tecton and available coordination sites on the metal centre. Since almost two decades, considerable effort has been invested in obtaining coordination networks and a large variety of examples have been reported. ${ }^{8-16}$

Molecular networks are defined by their dimensionality (1-, 240 or $3-D)$ which results from the number of translations in different directions of space operating on the assembling pattern. Within each dimensional category, these networks are defined by their geometry. For example, within 1-D networks, several types of arrangements (linear, stair type, zigzag type, ${ }_{45}$ helical, tubular etc.) may be formed. The geometry of the final assembly is obviously governed by both the structural and coordination features of the organic tecton and the metal centre. Dealing with linear and tubular coordination networks (Fig. 1), one may design an organic tecton offering four

[a] Laboratoire de Chimie de Coordination Organique, UMR CNRS 7140, Université Louis Pasteur, Institut Le Bel, 4,rue Blaise Pascal, F-67000 Strasbourg, France, hosseini@chimie.u-strasbg.fr

[b] A.E. Arbuzov Institute of Organic and Physical Chemistry, Russian Academy of Science, Arbuzov str. 8, Kazan 420088, Russian Federation [c] Kazan State University, Kremlevskaya str. 18, Kazan 420008, Russian Federation

$\dagger$ Electronic Supplementary Information (ESI) available: [Crystallographic data in cif format]. See http://dx.doi.org/10.1039/b000000x/
50 coordinating sites located in an alternate fashion above and below a cyclic unit ( $S 4$ symmetry). Using a metal connector adopting linear coordination geometry, one may envisage the formation of a tubular network (Fig. 1 top) in which the tecton behaves as tetrakis monodentate unit towards metal centres. ${ }_{55} \mathrm{We}$ have previously demonstrated this possibility by combining $[1,1,1,1]$-metacyclophane derivatives in 1,3alternate conformation bearing either four nitrile groups ${ }^{17}$ or four pyridyl units. ${ }^{18}$ with silver cation. In the case of tectons offering the proper orientation and an appropriate distance 60 between the coordinating sites on the same face allowing the two sites to bind to the same metal centre infinite 1-D nontubular architectures may be generated in the presence of metal centres adopting the tetrahedral coordination geometry (Fig. 1 bottom). We have also reported such a case using a ${ }_{65}$ calix[4] arene derivative in 1,3-alternate blocked conformation bearing four nitrile groups at the upper rim. ${ }^{19}$

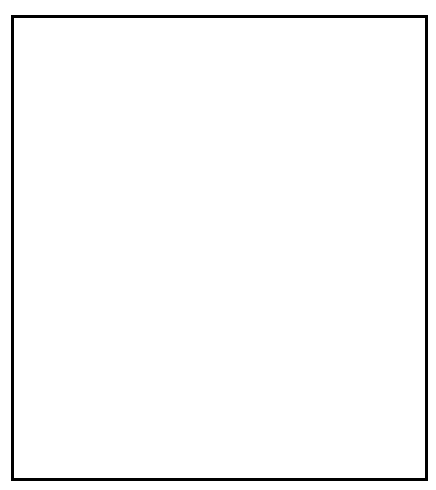

70 Fig. 1 Schematic representation of the formation of a tubular (top) or non-tubular (bottom) 1-D networks based on the self-assembly of a tecton bearing four coordinating sites occupying the apices of a tetrahedron and metal centres offering either linear or tetrahedral coordination geometries.

In this contribution, we report on the formation of three homometallic 1-D coordination networks based on combinations of $\mathrm{AgX}$ salts $\left(\mathrm{X}=\mathrm{BF}_{4}^{-}, \mathrm{PF}_{6}{ }^{-}\right.$and $\left.\mathrm{SbF}_{6}{ }^{-}\right)$and the p-tertbutylthiacalix [4]arene derivative $\mathbf{3}$ in 1,3-alternate 80 conformation bearing four butyronitrile groups at the lower 
rim (Scheme). The free ligand $\mathbf{3}$ and its analogue $\mathbf{2}$ bearing shorter spacers as well as the networks have been characterised in the crystalline phase by X-ray diffraction on single crystals.

${ }_{85}$ For the design principle of 1-D networks discussed above, the calix[4] arene ${ }^{20-21}$ and thiacalix[4] arene ${ }^{22-27}$ derivatives are interesting backbones. However, when unsubstituted at the lower rim, these tetraphenolic macrocycles are flexible entities and exist in solution as a mixture of four conformers

90 (cone $(\mathrm{C})$, partial cone (CP), 1,2-alternate (1,2-A) and 1,3alternate $(1,3-\mathrm{A}))$. In the solid state, both $p$ tertbutylcalix[4] arene ${ }^{28}$ and p-tertbutylthiacalix[4]arene $\mathbf{1}^{23}$ adopt the cone conformation. Among the four conformers, only the 1,3-A one fulfils the orientation requirement

${ }_{95}$ discussed above. Based on the calix[4]arene backbone, using the functionalisation of both the lower rim to impose the 1,3A conformation and the upper rim to introduce coordination sites, we have demonstrated the viability of the approach by generating 1-D silver coordination networks. ${ }^{19}$ One may also 100 envisage another strategy which consists of imposing the 1,3A conformation by functionalising only the lower rim with a fragment bearing at its extremity a monodentate coordination site. This was applied using the p-tertbutylthiacalix[4]arene for which only few examples of infinite coordination has been 105 reported. ${ }^{29-30}$

The design of compounds $\mathbf{2}$ and $\mathbf{3}$ (Scheme) is based on ptertbutylthiacalix[4]arene $\mathbf{1}$ in 1,3-A conformation as a backbone, four nitrile groups as coordinating sites and alkyl spacer connecting the two parts. The junction between the 110 calix and the spacer occurs at the lower rim and is ensured by an ether link. The two ligands $\mathbf{2}$ and $\mathbf{3}$ differ by the length of the spacer $\left(\mathrm{CH}_{2}\right.$ for $\mathbf{2}$ and $\left(\mathrm{CH}_{2}\right)_{3}$ for $\left.\mathbf{3}\right)$ connecting the nitrile group to the calix moiety. The length of the spacer was varied in order to explore its role on the conformational mobility of

115 the calix backbone. Indeed, as previously reported for calix[4] arene derivatives, ${ }^{20-21}$ whereas for $\mathbf{2}$ one would expect interconvertible conformers, for $\mathbf{3}$ blocked conformers should be obtained. Furthermore, for the 1,3-A conformer, the length of the spacer would allow to control the positioning and 120 distance of the nitrile groups with respect to the $p$-tertbutyl groups on the same face of the backbone.

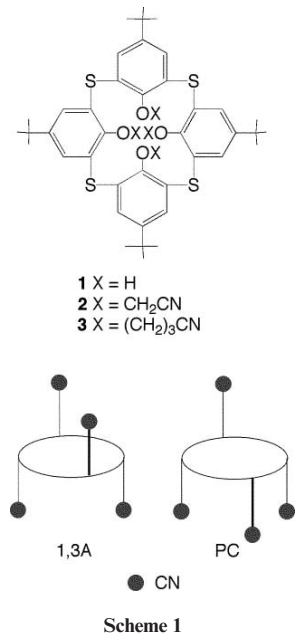

\section{Results and discussion}

The synthesis of $\mathbf{2}$ and $\mathbf{3}$ was rather straightforward (see 125 experimental part). The starting material for the preparation of $\mathbf{2}$ and 3 was $p$-tertbutylthiacalix[4]arene $1 .^{22}$ Both compounds $\mathbf{2}$ and $\mathbf{3}$ were obtained upon condensation of $\mathbf{1}$ with a $\omega$ halonitriles under basic conditions $\left(\mathrm{K}_{2} \mathrm{CO}_{3}\right)$ in refluxing dry acetone. Whereas for the synthesis of $\mathbf{2}$ the condensation was 130 performed between $\mathbf{1}$ and bromoacetonitrile, for the preparation of the compound 3, 4-chlorobutyronitrile was reacted with $\mathbf{1}$. For the compound 2, although overall yield was $76 \%$, in solution $\left(\mathrm{CDCl}_{3}\right){ }^{1} \mathrm{H}-\mathrm{NMR}$ investigations revealed the simultaneous presence of the partial cone (PC) 135 and 1,3-alternate (1,3-A) conformers in $1 / 1.5$ ratio at room temperature. The equilibrium between the two conformers could be shifted to $1 / 2$ by heating the solution to $50{ }^{\circ} \mathrm{C}$ for 30 minutes. Based on the nature of the spacer connecting the nitrile group to the calix oxygen atom $\left(\mathrm{CH}_{2}\right)$, this 140 conformational mobility is expected. In marked contrast, compound 3 was isolated in $67 \%$ yield under experimental conditions used, as a pure 1,3-A conformer. No interconversion between conformers was observed by NMR in $\mathrm{CDCl}_{3}$.

145 The solid state structure of both ligands 2 and 3 were investigated using X-ray diffraction on single crystal (see experimental part).

Although in $\mathrm{CDCl}_{3}$ solution, the compound 2 presents conformational mobility with the $\mathrm{PC}$ and 1,3-A conformers as 150 dominant species, upon crystallisation, only the 1,3-A conformer was obtained under the conditions used (see experimental part) (Figure 2). Compound 2 crystallises in the trigonal system (Space group P321). No solvent molecule is present in the lattice. The observed $\mathrm{C}-\mathrm{S}$ distance, in the range 155 of $1.76-1.80 \AA$, is in agreement with the one observed for the parent compound $1(1.79 \AA) .{ }^{23}$ For the ether junction between the calix and the pendent arms, the carbon to oxygen distances are in the range of $1.38-1.39 \AA$ for $\mathrm{O}-\mathrm{C}(\mathrm{Ph}))$ and $1.42-1.43$ $\AA$ for $\mathrm{C}$-O. The four nitrile groups $(\mathrm{C} \equiv \mathrm{N}$ distance of $1.10 \AA$ 160 and $1.14 \AA$ ) are located in an alternate fashion below and above the main plane of the thiacalixarene. The $\mathrm{CH}_{2} \mathrm{CN}$ fragments are almost linear with NCC angle of 173.3 and $178.5^{\circ}$. The pendent arms bearing the nitrile groups are oriented almost parallel to the calix long axis (CCO angle in 165 the range of $106.4^{\circ}$ and $109.0^{\circ}$, COC angle in the range of $110.2^{\circ}$ and $111.7^{\circ}$ ). The aromatic moieties on the same face of the molecule are almost parallel. It is worth noting that because of the short nature of the spacer connecting the nitrile group to the calix, the $\mathrm{CN}$ groups are in close proximity with 170 the t-butyl moieties located on the same face (distance in the range of $c a 3.6-4.6 \AA)$.

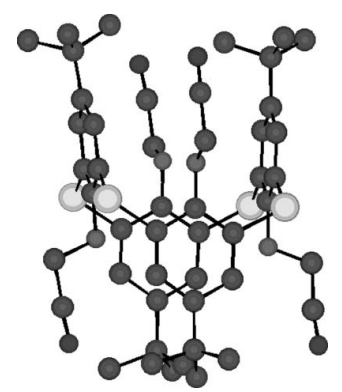

175 Fig. 2 The solid state structure of 2 showing the adopted 1,3alternate conformation. $\mathrm{H}$ atoms and solvent molecules are not presented for sake of clarity. For bond distances and angles see text. 
180 The packing of calix units $\mathbf{2}$ is rather peculiar as shown on figure 3 Indeed, among the three thiacalixarene moieties in the unit cell, two present short N-N distances of $3.88 \AA$ between nitrile groups belonging to two different calix 2 . (see below for comparison with the packing of free ligands $\mathbf{3}$ ). 185

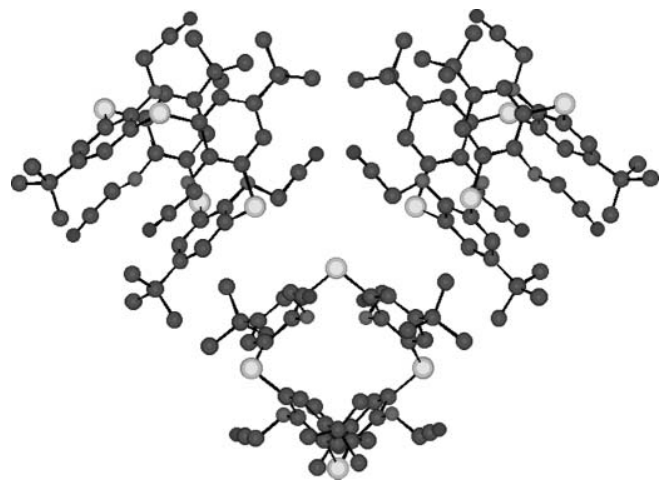

Fig. 3 Packing of three consecutive units 2 in the solid state (projection of the (001) plane). $\mathrm{H}$ atoms and solvent 190 molecules are not presented for sake of clarity. For bond distances and angles see text.

The solid state structure of the ligand $\mathbf{3}$ was also investigated by X-ray diffraction on single crystal (see experimental part). $195 \mathrm{As}$ in solution $\left(\mathrm{CDCl}_{3}\right)$, compound $\mathbf{3}$ adopts the 1,3-A conformation (Figure 4). Compound $\mathbf{3}$ crystallises in the orthorhombic system (Space group P222) with one $\mathrm{CHCl}_{3}$ solvent molecule. The latter occupies the empty space with no specific interactions with calix unit. The C-S distance, in the 200 range of $1.76-1.79 \AA$, is again in agreement with the one observed for 2 and for the parent compound 1 (1.79 $\AA) .{ }^{23}$ For the ether junction between the calix and fragments bearing the nitrile groups, the carbon to oxygen distances are in the range of $1.38-1.39 \AA$ for $\mathrm{O}-\mathrm{C}(\mathrm{Ph}))$ and $1.43-1.47 \AA$ for $\mathrm{C}-\mathrm{O}$. The 205 four nitrile groups $(\mathrm{C} \equiv \mathrm{N}$ distance in the range of $1.10-1.14$ $\AA$, NCC Angle in the range of $175.9-179.0^{\circ}$ ) are also located in an alternate fashion below and above the main plane of the thiacalixarene. However, in marked contrast with 2, among the four $\left(\mathrm{CH}_{2}\right)_{3} \mathrm{CN}$ groups $\left(\mathrm{CCO}\right.$ angle in the range of $106.5^{\circ}$ 210 and $110.0^{\circ}, \mathrm{COC}$ angle in the range of $111.0^{\circ}$ and $114.0^{\circ}$ ), three of them are oriented towards the exterior whereas one is pointing towards the interior. Again in contrast with 2, the aromatic rings on the same face of the molecule are not almost parallel but tilted leading to a flattened 1,3-A conformation. 215

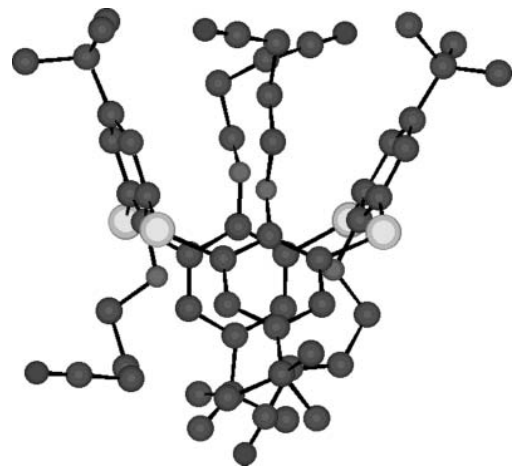

Fig. 4 The solid state structure of 3 showing the adopted 1,3alternate conformation. Among the four arms bearing the 220 nitrile groups, one is oriented outwardly. $\mathrm{H}$ atoms and solvent molecules are not presented for sake of clarity. For bond distances and angles see text.

Interestingly, in terms of packing, compounds $\mathbf{3}$ are arranged in a linear fashion along the $\mathrm{c}$ axis thus placing the nitrile 225 groups in ideal dispositions for binding of metal centres adopting the tetrahedral coordination geometry (Fig. 5).

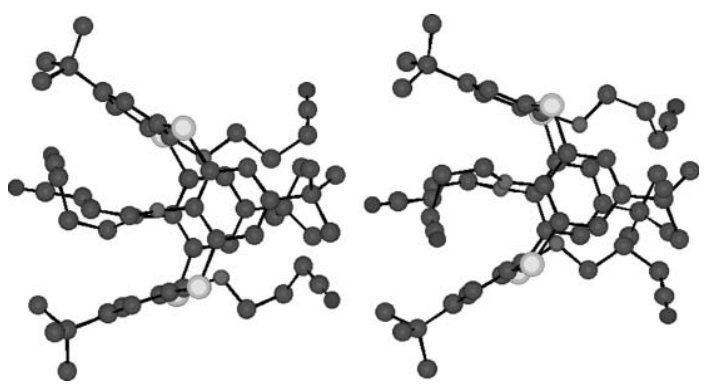

230 Fig. 5: Packing of consecutive calix units 3 in the solid state along the $\mathrm{c}$ axis showing the linear arrangement of ligands and the disposition of nitrile groups. $\mathrm{H}$ atoms and solvent molecules are not presented for sake of clarity. For bond distances and angles see text.

235

The propensity of both ligands $\mathbf{2}$ and $\mathbf{3}$ to behave as a tecton by forming infinite coordination networks was tested in the presence of silver cation. In order to study the possible role played by the anion, $\mathrm{BF}_{4}^{-}$and $\mathrm{XF}_{6}^{-}(\mathrm{X}=\mathrm{P}$ or $\mathrm{Sb}$ ) anions 240 possessing tetrahedral and octahedral coordination geometries respectively were used.

For the compound 2, although we have made several attempts based on many combinations of solvent and crystallisation conditions, unfortunately, we were unable to produce 245 crystalline material for structural investigations by X-ray diffraction methods. Based on the solid structure of $\mathbf{2}$ mentioned above (Fig. 2), this could have been anticipated for steric reasons. Indeed, because of the short nature of the spacer $\left(\mathrm{CH}_{2}\right)$ connecting the calix backbone to the nitrile 250 group, the formation of a 1-D network upon connection of consecutive units by silver cation must generate sever steric interactions, in particular between $t$-butyl groups belonging to consecutive calix units.

On the other hand, the inspection of the packing of compound ${ }_{255} 3$ in the crystalline phase (Fig. 5) clearly shows the proper predisposition of the units and thus the possibility of behaving as a coordinating tecton by bridging consecutive metal centres. This was indeed achieved by combining the tecton 3 with $\operatorname{AgX}\left(\mathrm{X}=\mathrm{BF}_{4}^{-}, \mathrm{SbF}_{6}^{-}\right.$and $\left.\mathrm{PF}_{6}^{-}\right)$. In all three cases, 260 suitable crystals for X-ray diffraction on single crystal have been obtained upon slow liquid-liquid diffusion at room temperature using either $\mathrm{CH}_{2} \mathrm{Cl}_{2}$ or $\mathrm{CHCl}_{3}$ to solubilize the tecton 3 and a $\mathrm{iPrOH}$ or EtOH solution of the silver salt (see experimental section). Since, independent of the nature of the 265 anion used, almost identical polycationic silver 1-D networks were obtained, here, we shall only discuss in detail the combination of 3 with $\mathrm{AgBF}_{4}$. In all three cases, the crystal is composed of neutral tecton $3, \mathrm{Ag}^{+}$cation, anion $\left(\mathrm{BF}_{4}^{-}, \mathrm{PF}_{6}^{-}\right.$or $\left.\mathrm{SbF}_{6}{ }^{-}\right)$and solvent molecules $\left(\mathrm{CHCl}_{3}\right.$ and $\mathrm{iPrOH}$ for $\mathrm{AgBF}_{4}$, $270 \mathrm{CHCl}_{3}$ for $\mathrm{AgSbF}_{6}$ and $\mathrm{CH}_{2} \mathrm{Cl}_{2}$ for $\mathrm{AgPF}_{6}$ ). In none of the 
three studied structures specific interactions between the $\mathrm{Ag}^{+}$ cation and anions could be observed. The solvent molecules present in the lattice occupy the empty space again with no specific interactions with 3 or $\mathrm{Ag}^{+}$cation. For all three 275 crystals, the $\mathbf{3} / \mathrm{Ag}^{+}$stoechiometry is $1 / 1$. When considering the interactions between organic tectons 3 and silver cations, the crystal may be described as 1-D cationic silver coordination networks separated by anions and solvent molecules. The cationic part of the crystal is generated by mutual 280 interconnection of organic moieties and metallic centres through nitrile silver interactions (Fig. 6). The other heteroatoms ( $\mathrm{O}$ and $\mathrm{S}$ ) are not involved in bonding interactions with the cation.

285

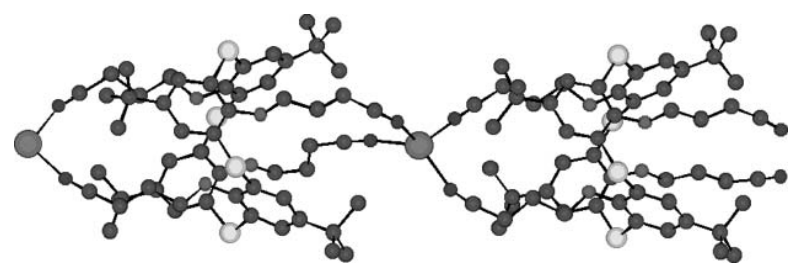

Fig. 6: A portion of the solid state structure obtained upon combining compound 3 with $\mathrm{AgBF}_{4}$ showing the mutual bridging between the organic tecton 3 and $\mathrm{Ag}^{+}$cations leading

290 to the formation of a cationic 1-D coordination network. $\mathrm{H}$ atoms, anions and solvent molecules are not presented for sake of clarity. For bond distances and angles see text.

For the organic tecton $\mathbf{3}$, as for its free form, it adopts the 1,3295 A conformation with the four nitrile groups $(\mathrm{C} \equiv \mathrm{N}$ distance in the range of $1.03-1.15 \AA$, NCC Angle in the range of 171.0 $177.2^{\circ}$ ) located in an alternate fashion below and above the main plane of the thiacalixarene. The $\mathrm{C}$-S distances, in the range of $1.76-1.79 \AA$, are close to those observed for the free 300 tecton 3. For the ether junction, the carbon to oxygen distances are in the range of $1.34 \AA-1.37 \AA$ for $\mathrm{O}-\mathrm{C}(\mathrm{Ph})$ and $1.41 \AA-1.46 \AA$ for $\mathrm{C}-\mathrm{O}$. In marked contrast with the free ligand 3, all four $\left(\mathrm{CH}_{2}\right)_{3} \mathrm{CN}$ groups ( $\mathrm{CCO}$ angle in the range of $100.9^{\circ}$ and $107.5^{\circ}$, COC angle in the range of $113.0^{\circ}$ and

$305115.4^{\circ}$ and OCCC dihedral angle in the range of -179.2 179.9) are almost fully stretched. As for the free ligand 3 , the aromatic rings on the same face of the molecule are tilted leading to a flattened 1,3-A conformation.

The $\mathrm{Ag}^{+}$cation (two crystallographically non equivalent) 310 connecting consecutive tectons $\mathbf{3}$ is tetra coordinated. Its coordination sphere is composed of four $\mathrm{N}$ atoms belonging to two consecutive tectons 3 (Ag-N distance in the range of 2.19 $-2.33 \AA$ ). The coordination geometry around the cation is a distorted tetrahedron (NAgN angle varying between $93^{\circ}$ and

$315124^{\circ}$ ). Due to the length and flexible nature of the spacer connecting the calix moiety to the nitrile group, tecton 3 behaves as a bischelating unit. Indeed, on each face of the molecule, two nitriles bind to the same silver cation.

The distances between consecutive $\mathrm{Ag}^{+}$cations within the 1-D 320 network are $c a 16.20$ and $16.46 \AA$. The shortest distances between $\mathrm{Ag}^{+}$cations belonging to two consecutive networks along the $\mathrm{a}$ and $\mathrm{b}$ axis are $15.00 \AA$ and $11.75 \AA$ respectively. In terms of packing (Fig. 7), the 1-D networks are arranged in parallel (along the a axis) and antiparallel (along the b axis) 325 fashions.

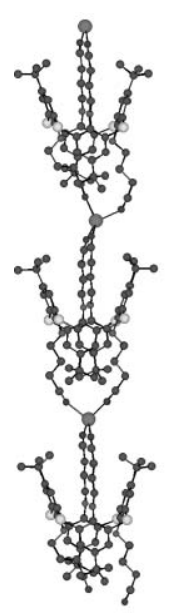

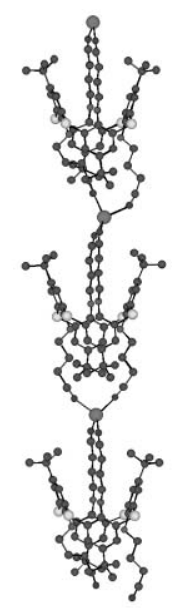

a)

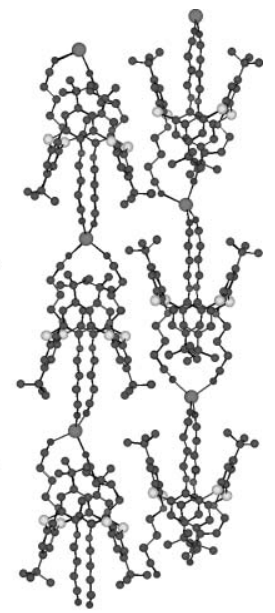

b)
Fig. 7: Packing of 1-D silver coordination networks generated 330 upon combining the tecton 3 with $\mathrm{AgBF}_{4}$ showing the parallel arrangement along the $a$ axis(a) and the antiparallel disposition along the $b$ axis (b) of consecutive 1-D networks in the crystal. $\mathrm{H}$ atoms, anions and solvent molecules are not presented for sake of clarity. For bond distances and angles 335 see text.

\section{Conclusions}

Both ligands $\mathbf{2}$ and $\mathbf{3}$ in the 1,3-alternate conformation offer four nitrile coordinating sites occupying the apices of a 340 pseudo tetrahedron. However, in the case of ligand $\mathbf{2}$ bearing four $\mathrm{CH}_{2} \mathrm{CN}$ groups, so far we have not been able to generate silver coordination networks. This may be due to the length of the spacer, a methylene groups, connecting the thiacalix backbone to the nitrile moiety which would generate steric 345 interactions between the $t$-butyl groups and the silver cation. On the other hand, for the ligand 3, the propyl spacer, connecting the nitrile to the oxygen atoms of the thiacalix, is long enough to avoid such a steric interactions and thus, allows the formation of linear 1-D silver coordination 350 networks in the presence of different silver salts. The ligand $\mathbf{3}$ behaves as a bischelating tecton, i.e. on each face of the unit the two nitrile groups coordinate to the same metal cation. Consequently, the formation of the network results from bridging of consecutive silver cations adopting tetrahedral 355 coordination geometry. Interestingly, the generation of the network is robust and independent of the nature of the anion. The combination of ligands reported here and longer analogues with other metal centres is currently under investigation. 360

\section{Experimental}

General: All reagents were purchased from commercial sources and used without further purification. p-tertButylthiacalix[4]arene 1 was prepared according to the 365 literature. ${ }^{22}{ }^{1} \mathrm{H}$ NMR spectra were recorded at room temperature on a Bruker $(300 \mathrm{MHz})$ NMR spectrometer. FTIR spectrum were recorded on a Perkin Elmer spectrometer. Mass spectra (MS(ES+)) were obtained on a MALDI-TOF Dynamo Finnigan mass spectrometer using 1,8,9- 
370 Trihydroxyanthracene or p-nitroaniline as matrix. Microanalyses were performed by the Service de Microanalyses de la Fédération de Recherche de Chimie, Université Louis Pasteur, Strasbourg.

\section{Synthesis}

375 25,26,27,28-tetrakis(O-cyanomethoxy)-5,11,17,23-tetra-p-tertbutyl-2,8,14,20-tetrathiacalix[4] arene (2)

A mixture of p-tert-butylthiacalix[4]arene $1(1.00 \mathrm{~g}, 1.39 \mathrm{mmol})$, $\mathrm{K}_{2} \mathrm{CO}_{3}(3.84 \mathrm{~g}, 27.78 \mathrm{mmol})$ and bromoacetonitrile $(1.94 \mathrm{~mL}$, $27.78 \mathrm{mmol})$ in dry acetone $(30 \mathrm{~mL})$ was refluxed under argon 380 for 48 hours. After cooling, the reaction mixture was evaporated to dryness, treated with $2 \mathrm{M} \mathrm{HCl}(60 \mathrm{~mL})$ and extracted with dichloromethane. The organic layer was dried over $\mathrm{MgSO}_{4}$, and the solvent removed. The residue was precipitated from a $\mathrm{CHCl}_{3}-$ pentane mixture and washed with methanol affording a white 385 solid $((0.92 \mathrm{~g}, 76 \%)$. NMR study revealed that the powder was composed of the compound $\mathbf{2}$ in PC and 1,3-A conformations in 1:1.5 ratio at room temperature. $\mathrm{mp}=335-337{ }^{\circ} \mathrm{C} .{ }^{1} \mathrm{H}$ NMR $\left(\mathrm{CDCl}_{3}\right): \delta=1.12(\mathrm{~s}, 18 \mathrm{H}, P C) ; 1.32(\mathrm{~s}, 36 \mathrm{H}, 1,3-A$. $) ; 1.34(\mathrm{~s}, 9 \mathrm{H}$, $P C) ; 1.46(\mathrm{~s}, 9 \mathrm{H}, P C) ; 4.31(\mathrm{~s}, 2 \mathrm{H}, P C) ; 4.78(\mathrm{~d}, 2 \mathrm{H}, \mathrm{J}=15.6 \mathrm{~Hz}$, $\left.{ }_{390} P C\right) ; 4.79(\mathrm{~s}, 8 \mathrm{H}, 1,3-A) ; 4.92(\mathrm{~s}, 2 \mathrm{H}, P C) ; 5.01(\mathrm{~d}, 2 \mathrm{H}, \mathrm{J}=15.3$ $\mathrm{Hz}, P C) ; 7.13(\mathrm{~d}, 2 \mathrm{H}, \mathrm{J}=2.7 \mathrm{~Hz}, P C) ; 7.59(\mathrm{~s}, 8 \mathrm{H}, 1,3-A) ; 7.60$ $(\mathrm{d}, 2 \mathrm{H}, \mathrm{J}=2.7 \mathrm{~Hz}, P C) ; 7.93(\mathrm{~s}, 2 \mathrm{H}, P C) .{ }^{13} \mathrm{C} \mathrm{NMR}\left(\mathrm{CDCl}_{3}\right): \delta=$ 149.3, 135.2, 134.7, 133.6, 132.8, 132.1, 128.3, 115.4, 58.7, 54.8, 34.5, 31.3, 31.2, 31.0, 29.7. FTIR (KBr): $v=2019 \mathrm{~cm}^{-1}(\mathrm{C} \equiv \mathrm{N})$. $395 \mathrm{MS}(\mathrm{ES}+), \mathrm{m} / z: 915\left(\mathrm{M}^{+} \mathrm{K}^{+}\right)$and $899\left(\mathrm{M}^{+} \mathrm{Na}^{+}\right)$. Anal.Calcd.: $\mathrm{C}$, $65.75 \%$; H, 5.94\%; N, 6.39\%. Found: C, 64.67\%; H, 5.92\%; N, $6.02 \%$

25,26,27,28-tetrakis[O-(3-cyano)propoxy]-5,11,17,23-tetra-ptertbutyl-2,8,14,20-tetrathiacalix[4]arene (3)

$400 \mathrm{~A}$ mixture of p-tert-butylthiacalix[4]arene 1 (2.50 g, $3.47 \mathrm{mmol})$, $\mathrm{K}_{2} \mathrm{CO}_{3}(9.60 \mathrm{~g}, 69.46 \mathrm{mmol})$, 4-chlorobutyronitrile $(5.2 \mathrm{~mL}$, $58.15 \mathrm{mmol})$, KI (catalytic quantity) in dry acetone $(65 \mathrm{~mL})$ was refluxed under argon for 56 hours. After cooling, the reaction mixture was evaporated to dryness, treated with $2 \mathrm{M} \mathrm{HCl}$ and 405 extracted with dichloromethane. The organic layer was separated, dried over $\mathrm{MgSO}_{4}$, and the solvent was removed. The solid residue was precipitated from a $\mathrm{CHCl}_{3}$-pentane mixture affording the pure compound 3 in the 1,3-A conformation as a white powder $(1.75 \mathrm{~g}, 67 \%) . \mathrm{mp}=367-370{ }^{\circ} \mathrm{C} .{ }^{1} \mathrm{H} \mathrm{NMR}\left(\mathrm{CDCl}_{3}\right): \delta=$ $4101.33(\mathrm{~s}, 36 \mathrm{H}) ; 1.42(\mathrm{~m}, 8 \mathrm{H}) ; 1.97(\mathrm{t}, 8 \mathrm{H}, \mathrm{J}=7.8 \mathrm{~Hz}) ; 3.97(\mathrm{t}, 8 \mathrm{H}$, $\mathrm{J}=6.6 \mathrm{~Hz}) ; 7.38(\mathrm{~s}, 8 \mathrm{H}) .{ }^{13} \mathrm{C} \mathrm{NMR}\left(\mathrm{CDCl}_{3}\right): \delta=156.1 ; 147.1$; $128.3 ; 127.6 ; 119.3 ; 66.6 ; 34.5 ; 31.4 ; 25.2 ; 13.8$. FTIR $(\mathrm{KBr}): v=$ $2243 \mathrm{~cm}-1(\mathrm{C} \equiv \mathrm{N}) . \mathrm{MS}(\mathrm{ES}+): 1027 \mathrm{~m} / z\left(\mathrm{M}^{+} \mathrm{K}^{+}\right)$. Anal.Calcd.: $\mathrm{C}$, $68.02 \%$; H, 6.88\%; N, 5.67\%. Found: C, 67.94\%; H, 7.12\%; N, $4155.56 \%$.

\section{Crystallisation conditions:}

Crystallisation of 2: A mixture of chloroform $(1.0 \mathrm{~mL})$ and 420 ethanol $(5.0 \mathrm{~mL})$ containing the ligand $2(20.0 \mathrm{mg})$ was refluxed for 6 hours. Upon cooling to room temperature, suitable colourless crystals for X-ray diffraction study were obtained after 2 days.

Cristallisation of 3: A mixture of chloroform $(3.0 \mathrm{~mL})$ and 425 ethanol $(1.0 \mathrm{~mL})$ containing the ligand $3(16.6 \mathrm{mg})$ was refluxed for 1 hour. Upon cooling to room temperature and slow evaporation, suitable colourless crystals for X-ray diffraction study were obtained after several days.

Cristallisation of $\left(3-\mathrm{AgBF}_{4}\right)_{\mathrm{n}}$ : In a crystallising tube, a 430 solution of $3(3.0 \mathrm{mg})$ in $\mathrm{CHCl}_{3}(1 \mathrm{~mL})$ was layered with a $\mathrm{CHCl}_{3}-i-\mathrm{PrOH} / 1: 1$ mixture $(0.25 \mathrm{~mL})$. A solution of $\mathrm{AgBF}_{4}$ $(7.8 \mathrm{mg})$ in ipropanol $(1 \mathrm{~mL})$ was carefully added. The slow diffusion at room temperature and in the dark produced colourless crystals after several days.

${ }_{435}$ Crystallisation of $\left(3-\mathrm{AgPF}_{6}\right)_{\mathrm{n}}$ : In a crystallising tube, a solution of $3(3.0 \mathrm{mg})$ in $\mathrm{CH}_{2} \mathrm{Cl}_{2}(1 \mathrm{~mL})$ was carefully layered with THF $(0.25 \mathrm{~mL})$ and then a solution of $\mathrm{AgPF}_{6}(7.7 \mathrm{mg})$ in EtOH $(1 \mathrm{~mL})$ was added. Upon slow diffusion at room temperature and in the dark, colourless crystals were obtained 440 after several days.

Cristallisation of $\left(3-\mathrm{AgSbF}_{6}\right)_{\mathrm{n}}$ : In a crystallising tube, a solution of $3(4.0 \mathrm{mg})$ in $\mathrm{CHCl}_{3}(1 \mathrm{~mL})$ was layered with a solution of $\mathrm{AgSbF}_{6}(13.7 \mathrm{mg})$ in ipropanol $(1 \mathrm{~mL})$. The slow diffusion at room temperature and in the dark produced 445 colourless crystals after several days.

\section{X-Ray Crystallography}

Data were collected at 173(2) K on a Bruker APEX8 CCD Diffractometer equipped with an Oxford Cryosystem liquid ${ }_{450} \mathrm{~N}_{2}$ device, using graphite-monochromated $\mathrm{Mo}-\mathrm{K} \alpha \quad(\lambda=$ 0.71073 ) radiation. For all structures, diffraction data were corrected for absorption and structural determination was achieved using the APEX (1.022) package. All hydrogen atoms have been calculated except those connected to 455 disordered atoms. CCDC ????-???? contains the supplementary crystallographic data for this paper. These data can be obtained free of charge at www.ccdc.cam.ac.uk/conts/retrieving.html or from the Cambridge Crystallographic data Centre, 12 Union Road, ${ }_{460}$ Cambridge CB2 1EZ, UK; Fax: (Internat.) +44-1223/336-033; E-mail:deposit@ccdc.cam.ac.uk.

Crystallographic data for 2: $\mathrm{C}_{48} \mathrm{H}_{52} \mathrm{~N}_{4} \mathrm{O}_{4} \mathrm{~S}_{4}, \mathrm{M}=877.18$, Trigonal, $a=b=18.5910(6) \AA, c=11.7442(7) \AA, \alpha=\beta=$ ${ }_{465} 90^{\circ}, \gamma=120^{\circ}, U=3515.3(3) \AA^{3}$, Space group $P 321, Z=3, \mu=$ $0.249 \mathrm{~mm}^{-1}$, Refls measured: 21748, Independent Refls : 5390, Final $R$ indices [I $>2 \operatorname{sigma}(\mathrm{I})]: R 1=0.0815, w R 2=$ $0.2107, G O F=1.035$.

Crystallographic data for 3: $\mathrm{C}_{56} \mathrm{H}_{68} \mathrm{~N}_{4} \mathrm{O}_{4} \mathrm{~S}_{4} \cdot \mathrm{CHCl}_{3}, \quad \mathrm{M}=$ 470 1108.75, Orthorhombic, $a=14.8603(8), b=15.2097(8) \AA ⿻ 丿$. $=25.1404(15) \AA, \alpha=\beta=\gamma=90^{\circ}, U=5682.3(5) \AA^{3}$, Space group $P 222, Z=4, \mu=0.357 \mathrm{~mm}^{-1}$, Refls measured : 34181 , Independent Refls : 12247, Final $R$ indices [I $>2$ sigma(I)]: $R 1=0.0695, w R 2=0.1422, G O F=1.039$.

${ }_{475}$ Crystallographic data for $\left(3-\mathrm{AgBF}_{4}\right)_{\mathrm{n}}$ : $\left(\mathrm{C}_{56} \mathrm{H}_{68} \mathrm{~N}_{4} \mathrm{O}_{4} \mathrm{~S}_{4} \mathrm{Ag}\right)_{4}$, $\left(\mathrm{BF}_{4}\right)_{4} \cdot\left(\mathrm{C}_{3} \mathrm{H}_{8} \mathrm{O}\right)_{3} \cdot\left(\mathrm{CHCl}_{3}\right)_{8}, \mathrm{M}=5871.48$, monoclinic, $a=$ $20.780(2), b=15.006(3) \AA, c=23.042(2) \AA, \beta=96.081(4)^{\circ}$, $U=7144.9(17) \AA^{3}$, Space group $P 2, Z=1, \mu=0.680 \mathrm{~mm}^{-1}$, Refls measured : 74628, Independent Refls : 30720, Final $R$ 480 indices $[\mathrm{I}>2 \operatorname{sigma}(\mathrm{I})]: R 1=0.1057, w R 2=0.2830, G O F=$ 1.038 .

Crystallographic data for $\left(3-\mathrm{AgSbF}_{6}\right)_{\mathrm{n}}$ : $\left(\mathrm{C}_{56} \mathrm{H}_{68} \mathrm{~N}_{4} \mathrm{O}_{4} \mathrm{~S}_{4} \mathrm{Ag}\right)_{4}$, $\left(\mathrm{SbF}_{6}\right)_{4} \cdot\left(\mathrm{CHCl}_{3}\right)_{14}, \mathrm{M}=6286.96$, monoclinic, $a=16.4840(3)$ $\AA, b=15.0260(4) \AA, c=28.9440(6) \AA, \beta=94.169(2)^{\circ}, U=$ ${ }_{485} 7150.1(3) \AA^{3}$, Space group $P 21 / c, Z=1, \mu=1.052 \mathrm{~mm}^{-1}$, Refls measured : 30216, Independent Refls : 17018, Final $R$ indices $[\mathrm{I}>2 \operatorname{sigma}(\mathrm{I})]: R 1=0.0952, w R 2=0.2798, G O F=$ 1.038 .

Crystallographic data for $\left(3-\mathrm{AgPF}_{6}\right)_{\mathrm{n}}: \quad\left(\mathrm{C}_{56} \mathrm{H}_{68} \mathrm{~N}_{4} \mathrm{O}_{4} \mathrm{~S}_{4} \mathrm{Ag}\right)$, $490\left(\mathrm{PF}_{6}\right) .\left(\mathrm{CH}_{2} \mathrm{Cl}_{2}\right)_{8}, \mathrm{M}=1412.08$, monoclinic, $\mathrm{a}=13.7751(4) \AA$, $b=15.2061(6) \AA, c=16.6762(4) \AA, \beta=94.453(3)^{\circ}, U=$ 3482.45(19) $\AA^{3}$, Space group $P 2, Z=2, \mu=0.645 \mathrm{~mm}^{-1}$, Refls measured : 17806, Independent Refls : 17706, Final $R$ indices $[\mathrm{I}>2 \operatorname{sigma}(\mathrm{I})]: R 1=0.0779, w R 2=0.2174, G O F=1.002$. 
Université Louis Pasteur, Institut Universitaire de France, the CNRS and the Ministry of Education and Research are acknowledged for financial support and for a partial scholarship to M. K. The work was also supported by RFBR (grant N 07-03-00834).

500

\section{Notes and references}

1 S. R. Batten and R. Robson, Angew. Chem. Int. Ed., 1998, 37, 1460.

2 S. Mann, Nature, 1993, 365, 499.

5053 J. D. Wuest, Chem. Comm., 2005, 5830

4 M. W. Hosseini, Acc. Chem. Res., 2005, 38, 313.

5 M. W. Hosseini, Cryst. Eng. Comm., 2004, 6, 318.

6 M. Simard, D. Su and J. D. Wuest, J. Am. Chem. Soc., 1991, 113, 4696.

5107 M. W. Hosseini, in NATO ASI Series, Eds. D. Braga, F. Grepiono, G. Orpen, Serie C, Kluwer, Dordrecht, Netherlands, 1999, 538, 181.

8 B. Moulton and M.J. Zaworotko, Chem. Rev., 2001, 101, 1629.

9 C. Janiak, Dalton Trans., 2003, 2781.

10 A. J. Blake, N. R. Champness, P. Hubberstey, W.-S. Li, M. A. Withersby and M. Schröder, Coord. Chem. Rev.,1999, 193, 117.

11 G. F. Swiegers and T. J. Malefetse, Chem. Rev., 2000, 100, 3483.

12 M. Eddaoui, D.B. Moler, H. Li, B. Chen, T.M. Reineke, M. O'Keefe and O. M. Yaghi, Acc. Chem. Res., 2001, 34, 319.

13 L. Carlucci, G. Ciani and D. M. Proserpio, Coord. Chem. Rev., 2003, $520 \quad \mathbf{2 4 6}, 247$.

14 S. Kitagawa, Angew. Chem. Int Ed., 2004, 43, 2434.

15 G. Férey, C. Mellot-Draznieks, C. Serre and F. Millange, Acc. Chem. Res., 2005, 38, 218.

16 D. Bradshaw, J. B. Claridge, E. J. Cussen, T. J. Prior and M. J. 525 Rosseinsky, Acc. Chem. Res., 2005, 38, 273.

17 C. Klein, E. Graf, M. W. Hosseini, A. De Cian, J. Fischer, Chem. Commun., 2000, 239.

18 G. Laugel, E. Graf, M. W. Hosseini, J.-M. Planeix, N. Kyritsakas, New J. Chem., 2006, 30, 1340.

53019 G. Mislin, E. Graf, M. W. Hosseini, A. De Cian, N. Kyritsakas, J. Fischer, Chem Commun., 1998, 2545.

20 C.D. Gutsche in Calixarenes Revised: Monographs in Supramolecular Chemistry Vol. 6, The Royal Society of Chemistry, Cambridge, 1998 .

53521 Z. Asfari, V. Böhmer, J. Harrowfield and J. Vicens in Calixarenes 2001, (Eds. Z. Asfari, V. Böhmer, J. Harrowfield and J. Vicens) Kluwer Academic, Dordrecht, 2001.

22 H. Kumagai, M. Hasegawa, S. Miyanari, Y. Sugawa, Y. Sato, T. Hori, S. Ueda, H. Kamiyama and S. Miyano, Tetrahedron Lett., 1997, 38, 3971.

23 H. Akdas, L. Bringel, E. Graf, M. W. Hosseini, G. Mislin, J. Pansanel, A. De Cian, J. Fischer, Tetrahedron Lett., 1998, 39, 2311.

24 M. W. Hosseini, ACS Series, Eds G. J. Lumetta, R. D. Rogers, A. S. Gopalan, 2000, 557, 296.

25 M.W. Hosseini in Calixarenes 2001, (Eds. Z. Asfari, V. Böhmer, J. Harrowfield and J. Vicens) Kluwer Academic, Dordrecht, 2001, pp. 110 .

55026 P. Lhoták, Eur. J. Org. Chem., 2004, 1675.

27 N. Morohashi, F. Narumi, N. Iki, T. Hattori, S. Miyano, Chem. Rev., 2006, 106, 5291

28 G. D. Andreetti, R. Ungaro, A. Pochini, Chem. Commun., 1979, 1005.

29 H. Akdas, E. Graf, M.W. Hosseini, A. De Cian, J.M. Harrowfield, Chem. Commun., 2000, 2219.

30 J. Sykora, M. Himl, I. Stobor, I. Cisarova, P. Lhotak, Tetrahedron., 2007, 63, 1675. 


\section{Graphical abstract}

The combination of a thiacalix[4]arene in 1,3-alternate conformation bearing four nitrile groups at the lower rim with silver cation leads, independent of the nature of the anion used, to the formation of 1-D coordination networks in the crystalline 565 phase.

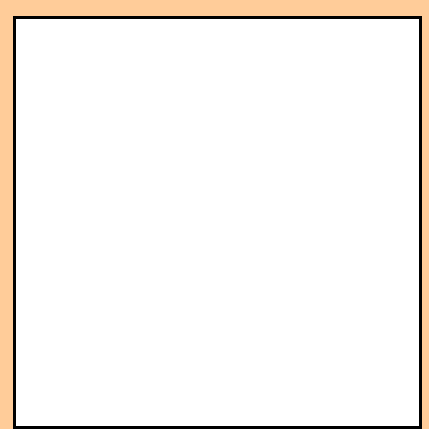

